\title{
Energy drinks on the island of Ireland; a nutritional and digital marketing overview
}

\author{
S. Gilpin, L. Keaver, M.S. Faughnan and C. Foley-Nolan \\ Safefood, Cork, Republic of Ireland
}

Information published in a recent World Health Organization (WHO) report ${ }^{(1)}$ identified an increase in the availability of energy drinks and the possible health risks from excessive consumption. Energy drinks availability was last reviewed on island of Ireland (IOI) in $2002^{(2)}$. Most energy drinks are classified as sugar-sweetened beverages and these have been shown to be associated with excess weight in adults and children ${ }^{(3)}$, thus contributing to the obesity problem.

The aim of this research was to provide an overview of the energy drinks available on the IOI including, caffeine, energy and sugar content, price, labelling and digital marketing strategies.

Sampling methodology was adapted from a validated method $^{(4)}$. Major food retailers were identified by market share ${ }^{(5)}$ and two supermarkets chosen from each of the following categories; multinational, convenience and discount stores in the Republic of Ireland and Northern Ireland. All available products were purchased in a one week period in February 2015. Information on the label, serving and product size and prices were recorded. Websites and social media channels were reviewed for each brand to identify event association, alcohol mention and target audience.

Overall 78 products were surveyed and 26 brands identified. Table 1 shows the analysis of the nutritional content of these energy drinks, serving size volumes ranged from $250 \mathrm{ml}$ to $500 \mathrm{ml}$ and a mean volume was used for analysis. Sugar-free or diet versions of the energy drinks and any extreme outliers were excluded from analysis.

Table 1: Mean values of nutritional content of available energy drinks on the IOI

\begin{tabular}{lcr}
\hline Mean Analysis & Per 100 ml & Per serving \\
\hline Energy (kJ) & $206 \cdot 6$ & $712 \cdot 4$ \\
Energy (kcal) & $48 \cdot 4$ & $169 \cdot 3$ \\
Sugar (g) & $10 \cdot 9$ & $37 \cdot 8$ \\
Caffeine (mg) & $31 \cdot 4$ & $125 \cdot 8$ \\
\hline
\end{tabular}

$91.1 \%$ of the energy drinks had labelling that complied with new food labelling legalisation introduced in $2014 .^{(6)}$ Sixteen of the brands had both a website and at least 1 social media account on any channel. One product referred to alcohol on their website. Young people were the predominant target of the brands $(50 \%)$ and extreme sports was the main event association (60\%).

In conclusion, there has been a 7.8 fold increase in the number of energy drinks available since 2002 on the IOI; this is in line with WHO findings.

1. Breda JJ, Whiting SH, Encarnação R et al. Energy drink consumption in Europe: A review of the risks, adverse health effects and policy options to respond. Front Public Health. 2014;2.

2. Safefood. A review of the health effects of stimulant drinks. Ireland: safefood, 2002 2002-03. Report No.: 1.

3. Malik VS, Pan A, Willett WC et al. Sugar-sweetened beverages and weight gain in children and adults: a systematic review and meta-analysis. Am $J$ Clin Nutr. 2013;98(4):1084-102.

4. Collins ML, MacMahon B, Weld G et al. A minimum standard of income for Ireland; a consensual budget standards study examining household. Ireland: The Policy Institute; 2012. 128 p. Report No.:27.

5. Kantar (2015) Big four supermarkets continue to find the market tough. http://uk.kantar.com/consumer/shoppers/2015/januarykantar-worldpanel-uk-grocery-share-data/ (accessed January 2015).

6. Food Safety Authority of Ireland. Overview of Changes to Food Labelling Introduced under the New Food Information Regulation. Ireland: Food Safety Authority of Ireland; July 2012. 16p. Report No.:1. 